Provided for non-commercial research and education use. Not for reproduction, distribution or commercial use.

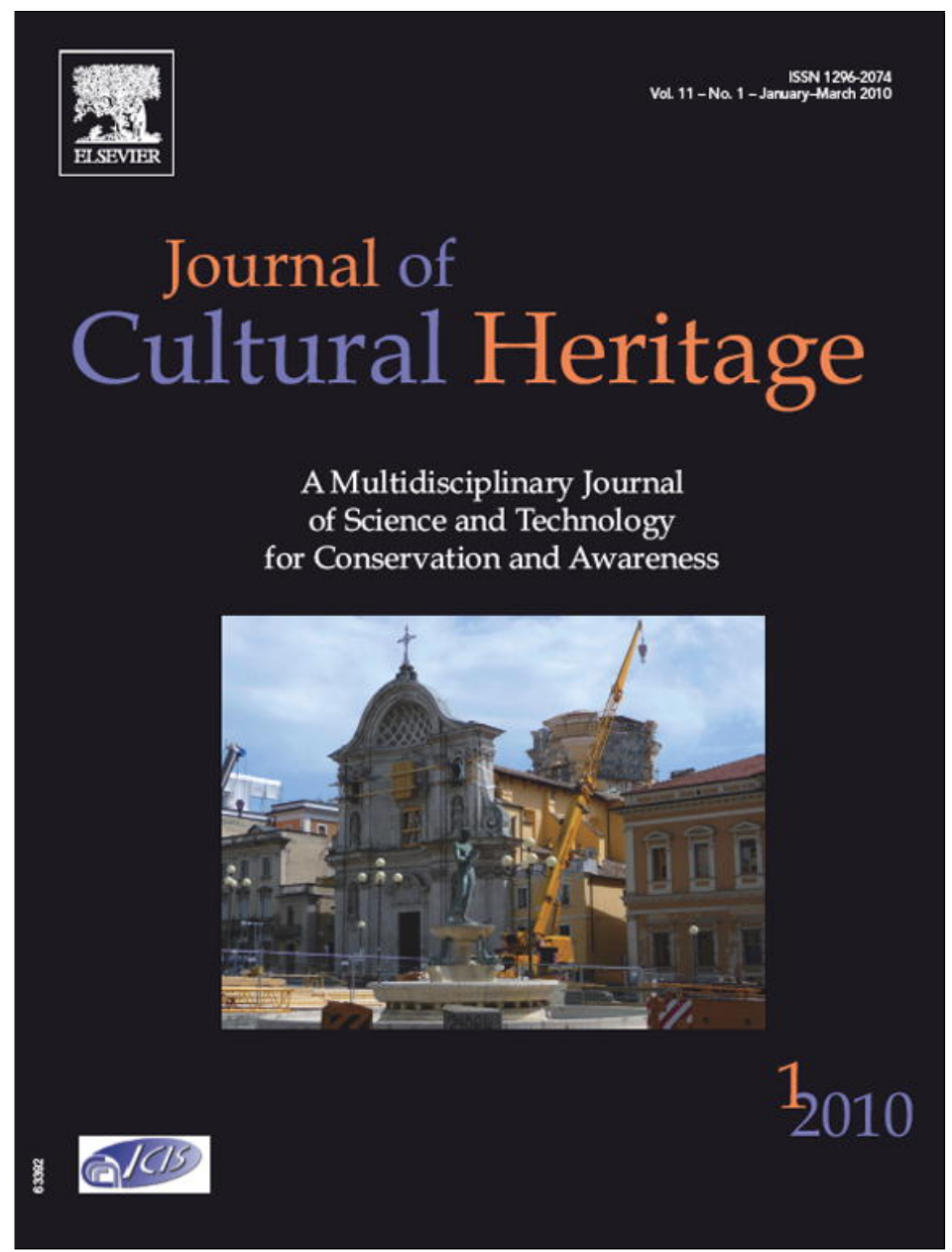

This article appeared in a journal published by Elsevier. The attached copy is furnished to the author for internal non-commercial research and education use, including for instruction at the authors institution and sharing with colleagues.

Other uses, including reproduction and distribution, or selling or licensing copies, or posting to personal, institutional or third party websites are prohibited.

In most cases authors are permitted to post their version of the article (e.g. in Word or Tex form) to their personal website or institutional repository. Authors requiring further information regarding Elsevier's archiving and manuscript policies are encouraged to visit:

http://www.elsevier.com/copyright 
Original article

\title{
Non-invasive characterisation of binding media on painted glass magic lantern plates using mid-infrared fibre-optic reflectance spectroscopy
}

\author{
Rebecca Ploeger ${ }^{1}$, Dominique Scalarone ${ }^{2}$, Oscar Chiantore* \\ Department of IPM Chemistry and NIS (Nanostructured Surfaces and Interfaces) Centre of Excellence, \\ University of Torino, Via Pietro Giuria, 7, 10125, Torino, Italy \\ Received 4 July 2008; accepted 28 January 2009 \\ Available online 13 November 2009
}

\begin{abstract}
Painted glass magic lantern plates from the Museo Nazionale del Cinema, Torino (Italy), were studied using mid-infrared (mid-IR) fibre-optic reflectance spectroscopy (FORS), a non-invasive technique, to test its potential for the identification of the types of binding media used in the paints. Gum, oil and resin media were identified on the plates and the amounts of these media varied from place to place; the discovery of these media correlate well with the literature on magic lantern plate preparation and painting. The spectra collected are reported uncorrected and also with the fingerprint region corrected with the Kramers-Kronig correction, which corrects distorted peaks caused by specular reflections.

(C) 2009 Elsevier Masson SAS. All rights reserved.
\end{abstract}

Keywords: Magic lanterns; Painted glass plates; Fibre-optic reflectance spectroscopy; Non-invasive techniques; Natural paint binders

\section{Introduction}

Mid-IR fibre-optic reflectance spectroscopy (FORS) is a noninvasive and flexible technique which allows one to examine unique objects and materials. This technique has been used in the conservation field for about 10 years [1,2] and continues to gain popularity. The fibre-optic probe is designed to be coupled with a Fourier transform infrared (FTIR) bench unit and contains a bundle of fibres, transparent in the mid-IR spectral region, with a number dedicated to directing the radiation to the object and the others dedicated to directing the radiation reflected back from the object. In situ, mid-IR measurements on objects are possible if the fibres are coupled with a portable spectrophotometer. The analyses can be done with or without contact with the surface of the material and perpendicular or angled, as desired for optimising the collected spectrum [3].

Painted glass magic lantern plates are delicate objects, thus a non-invasive and non-destructive technique, such as mid-IR

\footnotetext{
* Corresponding author. Tel.: +39 011 6707558; fax: +39 0112367558

E-mail addresses: rebecca.ploeger@unito.it (R. Ploeger), dominique.scalarone@unito.it (D. Scalarone), oscar.chiantore@unito.it (O. Chiantore).

1 Tel.: +39 011 6707554; fax: +390116707855

2 Tel.: +39011 6707546; fax: +390116707855.
}

FORS, is ideal for the characterisation of the binding media present on these plates. Described as the ancestors of the modern slides for slide projectors, the plates consisted of a carefully painted image on a clear glass surface which was held in place by wood or another type of support. The slide image was projected onto a suitable screen by a magic lantern and was an early form of entertainment and also used for scientific optical experiments [4]. The projection was done by passing a bright beam of light through the slide followed by an enlarging lens.

Though the 15 th to the 19 th centuries, the images on the magic lantern slides were painted by hand; these elaborate hand-painted glass slides are considered to be miniature masterpieces of their own. With the invention of photography in the 19th century, photographic plates quickly became popular, and hand painting on glass became almost a lost art [4]. Since this paper focuses on hand-painted glass plates, photographic magic lantern plates will not be discussed. The main painting techniques described in the literature involved watercolour and oil, and often both on the same piece of glass. Sometimes tempera (animal glue) was also used. In some cases, to help realise the design, a very thin layer of varnish, diluted gelatin or a solution of water and sugar was first placed on the glass. This allowed the artist to lightly draw a design on top with a thin brush and black pigments or a neutral colour, with a pencil, with chalk or with calcium carbonate. A more simple method, with lower quality 
results, was to trace a design on a sheet of gelatin using a thin point and carefully rubbing a fine powder of lead on the surface, which was deposited in the incisions. Another method frequently used, especially to obtain realistic images, was to place a clean glass over a design and copy it directly using coloured paints without creating an outline. [4].

The oil colour technique used the more transparent traditional oil colours. The paint was added in at least three layers, where the second and third layers were painted with more luminous and pure colours. Once complete, the paint surfaces were cleaned and varnished, where necessary, with a very dilute varnish. For the painted glass magic lantern plates, where fine details and clarity were essential, a fine design was first laid-out on a flat piece of glass and coloured in with watercolours over which was spread a layer of varnish to give the necessary transparency to the image. This method was established and used by the British microscopist Rev. Dr D. Dallinger in the 19th century [4].

The spectra obtained by mid-IR FORS are generally low in intensity (reflected energy is usually in the range of $1-2 \%$ [2]), noisy [2] and complicated; thus, making them difficult to interpret. Distortions in the spectra, such as shifts in absorption frequencies and changes in peak shapes are also observed in mid-IR FORS spectra making them difficult or impossible to compare with transmission and ATR spectra [2,3]. Many of these distortions originate from specular reflection; these distortions, including reststrahlen (residual energy) bands and peaks which resemble first order derivatives, must be carefully interpreted and corrected, when possible. Also surface topography and geometry have effects on the shapes of the spectra [5]. In some cases, spectral corrections can be employed to aid in the interpretation of the results. For example, with some spectral distortions caused by specular reflection the Kramers-Kronig correction can be used $[1,2,6]$. Also, the specular component of the reflection can be decreased by the inclination of the fibres; however, this leads to signal loss [3]. When using the Kramers-Kronig correction, special attention should be paid [6] to the algorithm in the software concerning the correction to ensure that it is valid for the case at hand.

Another important point is the possibility of interferences between adjacent thin layers, which has been observed using mid-IR FORS. Unfortunately, it is impossible to discriminate between separate layers during spectra collection and personal judgement based on other knowledge of the artwork must be used for spectra interpretation.

Mid-IR FORS can be considered a complementary technique to Raman spectroscopy. Raman spectroscopy, although having a higher signal output, resolution and less noise problems, can suffer from fluorescence from the organic materials complicating significantly spectra interpretation. In cases where fluorescence is an issue, mid-IR FORS can be a useful tool for organic binder identification.

Presented in this paper are mid-IR FORS characterisation results of the binding materials used in the painted images on two glass magic lantern plates from the Museo Nazionale del Cinema's collection in Torino, Italy. The two magic lantern glass plates studied were Ponte del Diavolo-Giorno and Ponte del
Diavolo-Notte and are described in more detail in the experimental section.

\section{Experimental}

Reflectance spectra were acquired using a Thermo Nicolet FTIR-NEXUS spectrophotometer, connected to a REMSPEC fibre-optic immersion probe and a liquid nitrogen cooled Mercury Cadmium Telluride (MCT) detector. The Y-shaped fibre-optic probe had a tip length of $10 \mathrm{~mm}$ with fibres $(500 \mu \mathrm{m}$ each in diameter) made of chalcogenide, with a glass core matrix of an As-Se-Te mixture and a As, Se, S glass cladding mixture. The probe contained a 19-fibre bundle; seven fibres sent the radiation to the sample, and the other 12 were dedicated to guiding the reflected energy to the detector. Spectra were collected from $4000 \mathrm{~cm}^{-1}$ to $1000 \mathrm{~cm}^{-1}$ with $4 \mathrm{~cm}^{-1}$ resolution and 128 scans. A polished piece of aluminium was used as the reference material for the background spectrum. The probe, securely mounted with a retort stand with clamps, was kept at a $90^{\circ}$ angle to the sample surface and a small space of approximately $1 \mathrm{~mm}$ was left between the probe and sample surface. This distance was chosen to minimise the risk of accidental contact with the surface of the plate still having a relatively good signal. If the probe is too far from the surface, much of the signal is lost and the spectra become much lower in intensity. Data was collected and analysed in OMNIC 6.1 a software. Employed in some cases to help with the interpretation of the spectra was the Kramers-Kronig correction. The spectra were all smoothed to $25 \mathrm{~cm}^{-1}$. The probe set-up can be seen in Fig. 1.

Some limitations of the fibres and technique are undesired absorptions; the fibres show an $\mathrm{Se}-\mathrm{H}$ stretching absorption in the 2050 to $2250 \mathrm{~cm}^{-1}$ range altering the signal to noise ratio in that region. Environmental moisture at $3100-3500 \mathrm{~cm}^{-1}$ and carbon dioxide at $2250 \mathrm{~cm}^{-1}$ can also cause interference, blinding the regions $[1,7]$.

FTIR-attenuated total reflectance (ATR) spectra were collected with a Smart Endurance ATR accessory, from $4000 \mathrm{~cm}^{-}$ to $500 \mathrm{~cm}^{-1}$ and for 32 scans and a resolution of $4 \mathrm{~cm}^{-1}$.

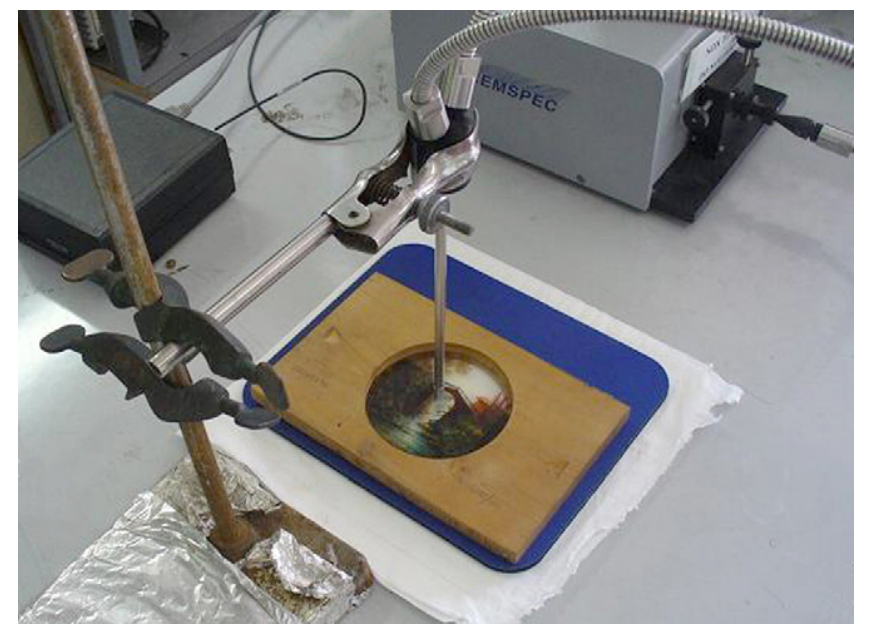

Fig. 1. Ponte del Diavolo-Giorno (painted side of glass plate) and fibre-optic probe set up. 


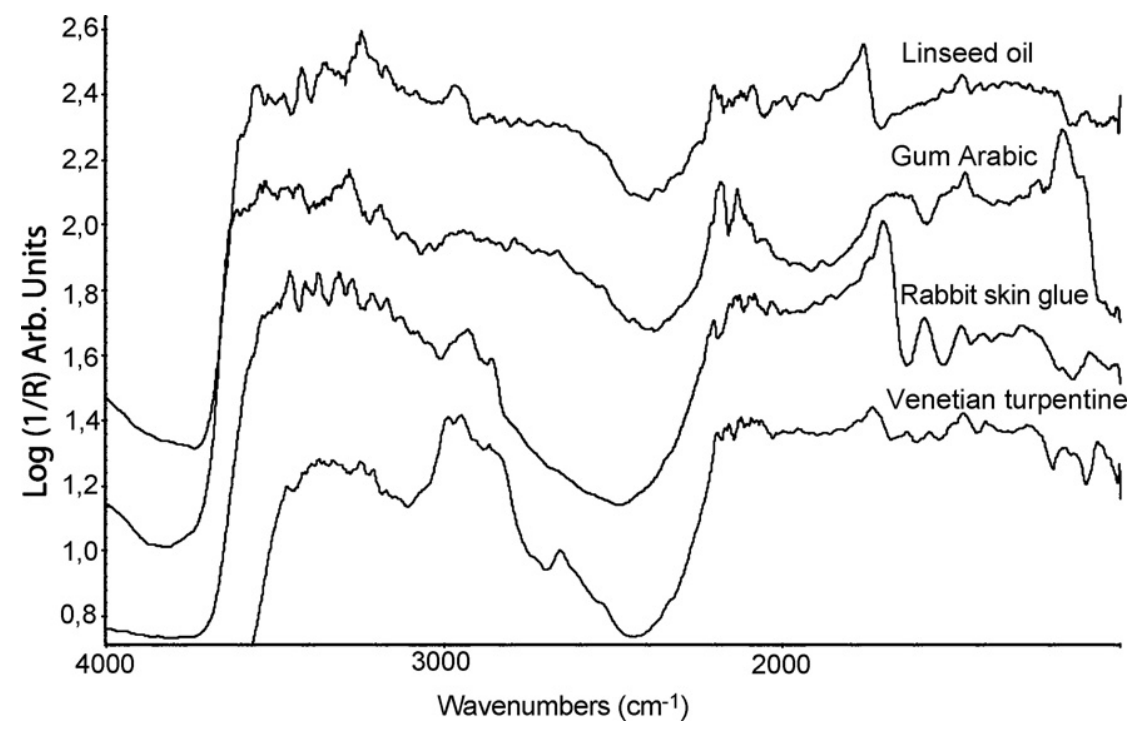

Fig. 2. Mid-infrared (IR) spectra (uncorrected) of the four reference materials. From top to bottom: linseed oil, gum arabic, rabbit skin glue and Venetian turpentine. Taken at a $90^{\circ}$ angle to the sample surface. Arbitrary axis, smoothed by $25 \mathrm{~cm}^{-1}$.

The painted glass magic lantern plates were Ponte del Diavolo-Giorno (The Devil's Bridge-Day) and Ponte del Diavolo-Notte (The Devil's Bridge-Night). Both plates were from Germany and were made in the second half of the 19th century. They were designed to be "dissolving views", both having the same scene: a bridge, house and countryside at two different moments during the day. One plate represented the scene in the daylight with the light of the sun and the other represented the scene in the twilight of the night. Placed over one another during the projection gave the effect of the transition between day and night.

Reference samples were prepared on glass microscope slides and measured the same way as the glass magic lantern plates. Thin film reference samples of clarified linseed oil (used to represent an oil paint, from Lefranc \& Bourgeois, France), rabbit skin glue (bulk from Rima, a local art supplies store), gum arabic (Water Colour from Winsor \& Newton, England) and Venetian turpentine (from Talens, Holland) were prepared and analysed for comparison purposes.

\section{Results and discussion}

The reference materials were helpful for the interpretation of the spectra collected on the painted glass magic lantern plates. Oil colours (linseed oil), watercolours (natural gums) and tempera (animal glues) were the most widely used painting materials for glass magic lantern plates, as well as varnish materials; thus, reference samples of these materials were prepared. Linseed oil (uncorrected) had a characteristic first order derivative specular distortion $\mathrm{C}=\mathrm{O}$ vibration peak at $1754 \mathrm{~cm}^{-1}$. Also present, were the $\mathrm{CH}_{2}$ stretching peaks at approximately $2951 \mathrm{~cm}^{-1}$ and $2850 \mathrm{~cm}^{-1}$ and in the noisier fingerprint region there were peaks around $1478 \mathrm{~cm}^{-1}$ and $1252 \mathrm{~cm}^{-1}$. Gum arabic (uncorrected) had a very characteristic distorted $\mathrm{C}-\mathrm{O}$ peak at $1170 \mathrm{~cm}^{-1}$ and peaks at $1456 \mathrm{~cm}^{-1}$ and $1670 \mathrm{~cm}^{-1}$. Rabbit skin glue (uncorrected) had a very characteristic first order distorted peaks at
$1704 \mathrm{~cm}^{-1}$ from the $\mathrm{C}=\mathrm{O}$ in the amide group of the protein (amide I) and $1578 \mathrm{~cm}^{-1}$ from the $\mathrm{C}-\mathrm{N}-\mathrm{H}$ bending vibration of the protein (amide II). The Venetian Turpentine reference (uncorrected) had a characteristic distorted $\mathrm{C}=\mathrm{O}$ peak around $1735 \mathrm{~cm}^{-1}$ and fingerprint peaks at approximately $1465 \mathrm{~cm}^{-1}$, $1274 \mathrm{~cm}^{-1}, 1147 \mathrm{~cm}^{-1}$ and $1065 \mathrm{~cm}^{-1}$. The reference spectra can be seen in Fig. 2. To help in the interpretation of the distorted spectra, the Kramers-Kronig correction was applied to the fingerprint regions, and it can be seen in Fig. 3 how successful the correction was in correcting the specular distortions in the reference spectra. Shown are the corrected fingerprint regions of each reference spectra compared to their FTIR-attenuated total reflectance (ATR) spectra respectively. In all the cases, except for part of the turpentine spectrum, the Kramers-Kronig correction worked well to correct the spectra, making them appear in a more traditional fashion. It should be noted that the mid-IR FORS spectra and FTIR-ATR spectra have different resolutions, $25 \mathrm{~cm}^{-1}$ and $4 \mathrm{~cm}^{-1}$ respectively. As a result, the spectra shapes and relative position of the peaks were compared, since exact peak matching is not possible.

An important observation to note is the shifting of the peaks to longer wave numbers in the FORS spectra compared to the values reported for transmission and attenuated total reflectance spectra. This is likely due to the contribution of the specular reflection [7]. Other phenomena observed were the distortions of some of the main absorbance peaks into peaks resembling first order derivatives and reststrahlen bands due to the intense reflectance maxima.

Ten areas were examined on each piece (Figs. 4a and b), with the probe at a $90^{\circ}$ angle to the sample surface. Unfortunately, since the Ponte del Diavolo-Notte was so heavily damaged, the sample points between the two plates do not correspond with each other. Observed were variations of the paint binder composition from area to area; in each point the components remained the same but varied in concentration. On the Ponte del Diavolo-Giorno and Notte, the binding materials identified 

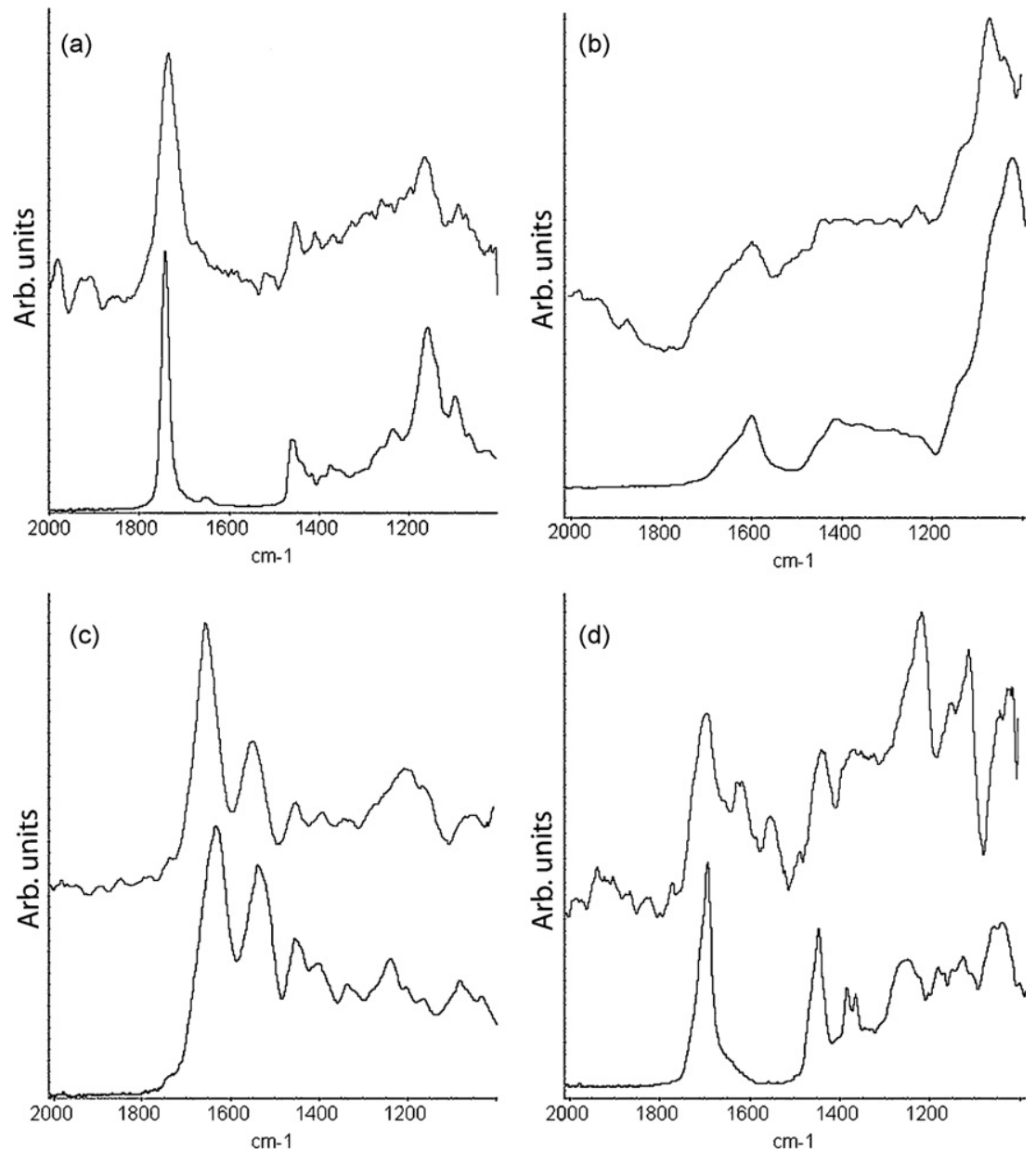

Fig. 3. The Kramers-Kronig corrected fingerprint regions (top spectra) of the reference spectra compared to the FTIR-ATR spectra (bottom spectra) of the same materials respectively: a: linseed oil; b: gum Arabic; c: rabbit skin glue and d: Venetian turpentine.

were oil, watercolour (gum arabic or a gum or sugar material with a similar infrared spectrum) and a resin. The gum material observed was likely part of a preparatory layer, since it was more prevalent in areas without much colour. Also suspected was an

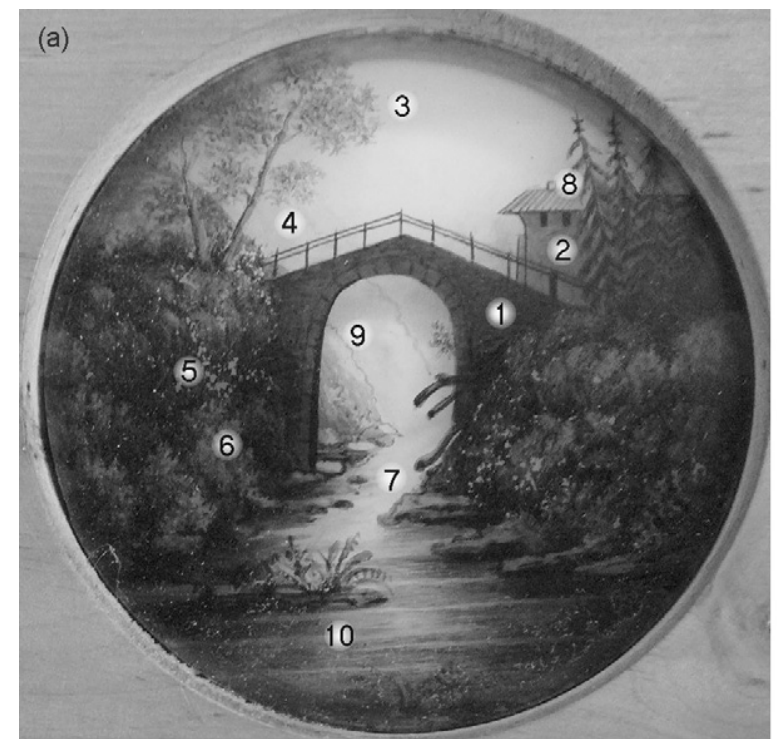

oil/resin paint-binding material or a varnish layer or layers over an oil paint. In some spectra there were distortions resembling reststrahlen bands that distorted much of the fingerprint region making binder identification very difficult or impossible.

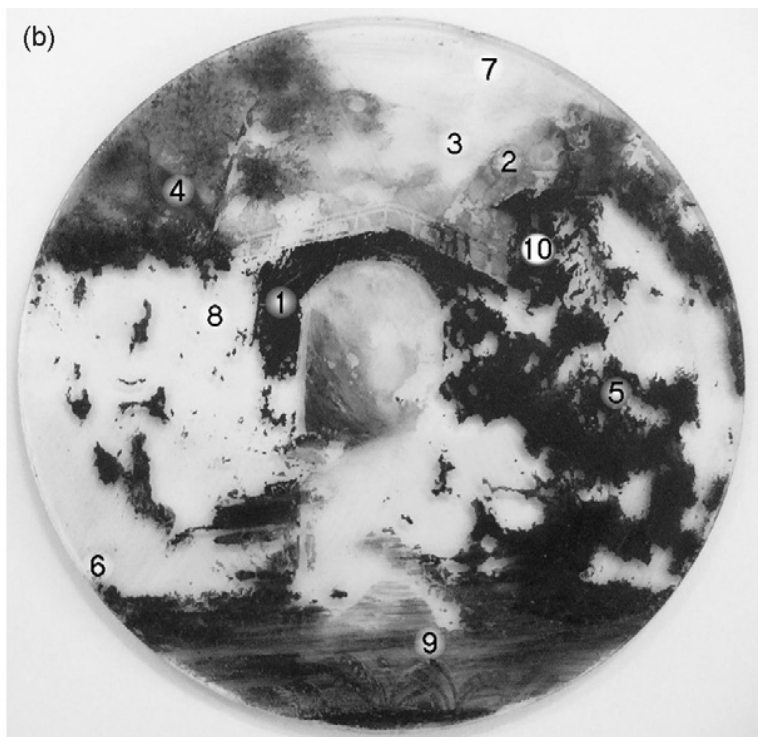

Fig. 4. The sample points on the Ponte del Diavolo-Giorno (a) and Ponte del Diavolo-Notte (b). 

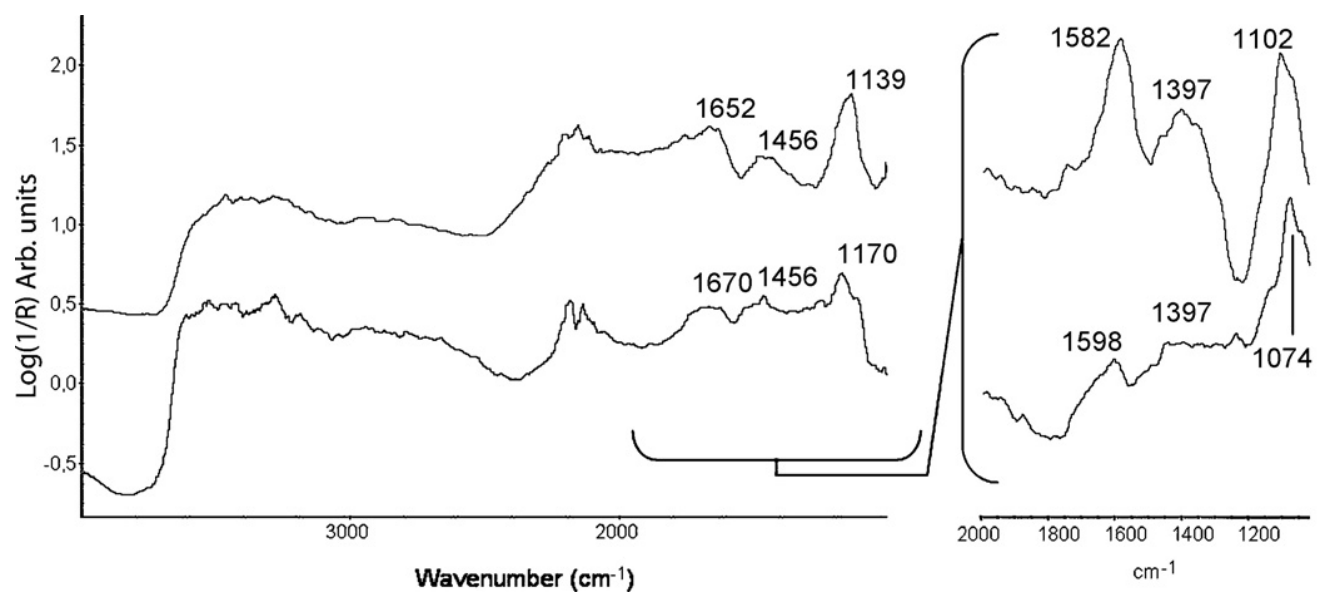

Fig. 5. Sample point 8, a pinkish part of the sky on Ponte del Diavolo-Giorno compared to the gum arabic reference. To the right, is the Kramers-Kronig corrected fingerprint region of the two spectra.
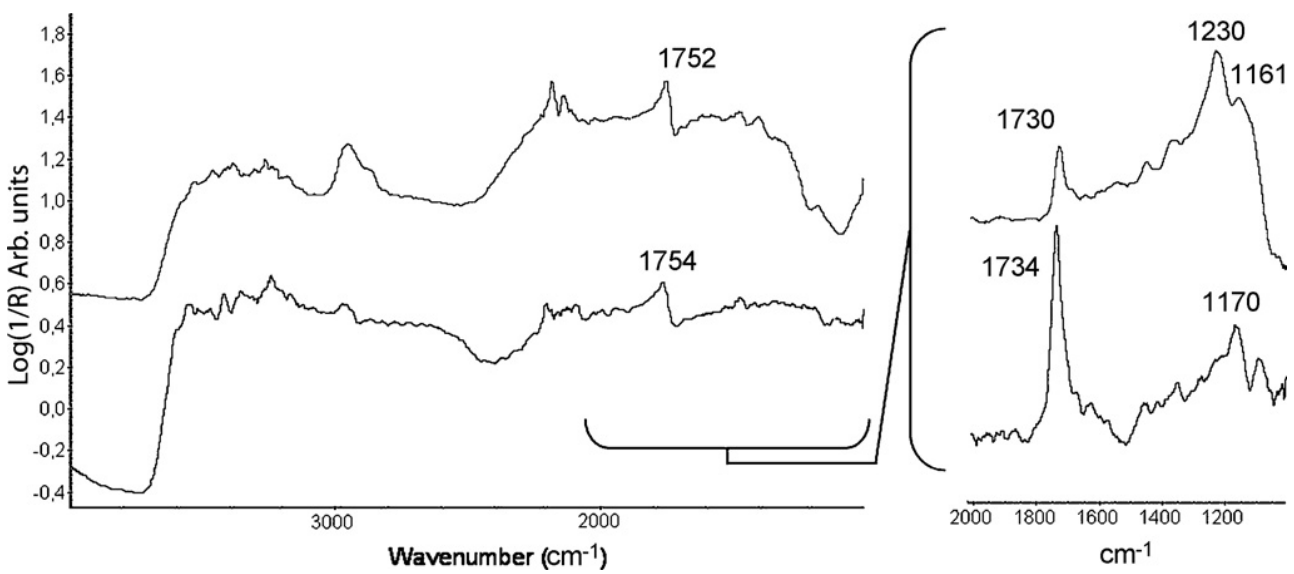

Fig. 6. Sample point 10, blue water on Ponte del Diavolo-Giorno, compared to the linseed oil reference. To the right, is the Kramers-Kronig corrected fingerprint region of the two spectra.

Fig. 5 shows the spectrum of point 8, a pinkish part of the sky above the roof, taken on the Ponte del Diavol-Giorno with the gum arabic reference sample. This spectrum corresponded well with the gum reference with overlapping peaks at approximately
$1652 \mathrm{~cm}^{-1}, 1456 \mathrm{~cm}^{-1}$ and $1139 \mathrm{~cm}^{-1}$. The Kramers-Kronig corrected absorbances show a better correspondence between the two spectra. Fig. 6 shows the spectrum of point 10, blue water, sampled on the same magic lantern plate with the oil

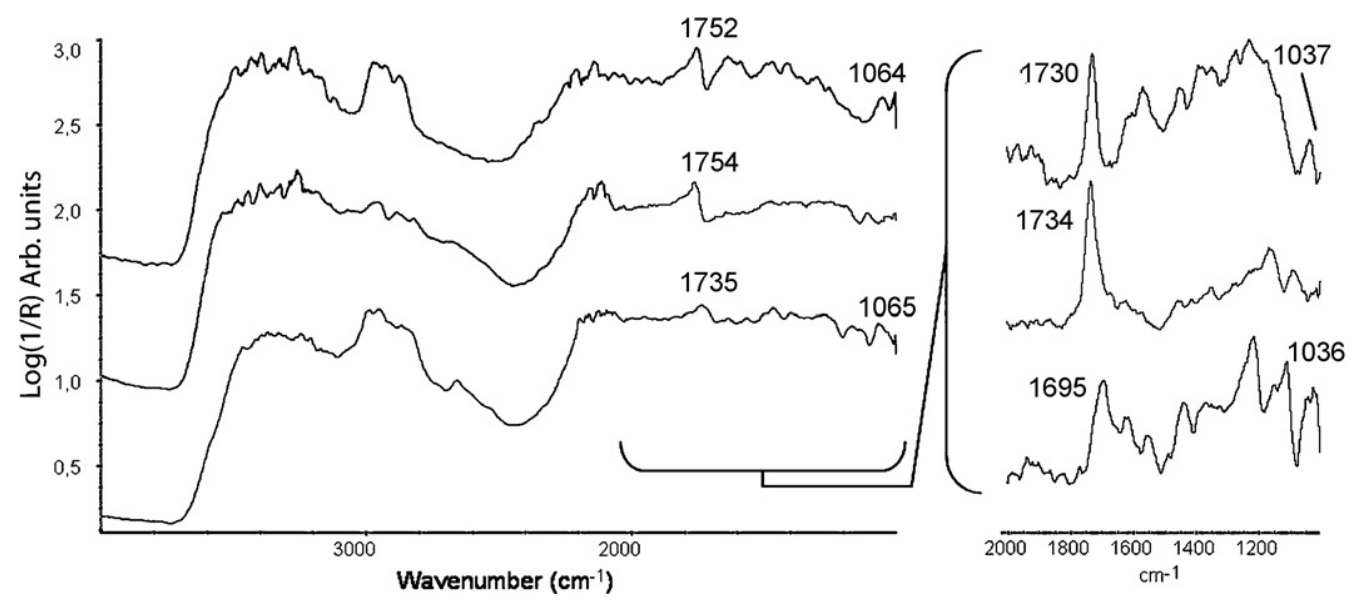

Fig. 7. Sample point 2, a brown part of the building on Ponte del Diavolo-Giorno, compared to the linseed oil and Venetian turpentine references. To the right, is the Kramers-Kronig corrected fingerprint region of the three spectra. 
Table 1

Binders identified with mid-infrared (IR) fibre-optic reflectance spectroscopy (FORS) at the various points (as indicated in Figs. 4a and b) for the two glass magic lantern plates studied.

\begin{tabular}{|c|c|c|c|c|c|c|c|c|c|c|c|}
\hline & Sample points & 1 & 2 & 3 & 4 & 5 & 6 & 7 & 8 & 9 & 10 \\
\hline \multirow[t]{3}{*}{ Ponte del Diavolo-Giorno } & Gum & & & $\sqrt{ }$ & $\diamond$ & $\diamond$ & & a & $\sqrt{ }$ & $\diamond$ & $\diamond$ \\
\hline & Oil & $\sqrt{ }$ & $\sqrt{ }$ & & $\sqrt{ }$ & $\diamond$ & $\sqrt{ }$ & $\sqrt{ }$ & & $\sqrt{ }$ & $\sqrt{ }$ \\
\hline & Resin & a & $\sqrt{ }$ & & & $\diamond$ & a & & & & \\
\hline \multirow[t]{3}{*}{ Ponte del Diavolo-Notte } & Gum & $\diamond$ & a & $\sqrt{ }$ & a & & & & & & $\diamond$ \\
\hline & Oil & $\diamond$ & $\sqrt{ }$ & & $\sqrt{ }$ & $\diamond$ & $\diamond$ & $\sqrt{ }$ & $\sqrt{ }$ & $\sqrt{ }$ & $\diamond$ \\
\hline & Resin & & & & $\sqrt{ }$ & $\diamond$ & $\diamond$ & $\mathrm{a}$ & $\mathrm{a}$ & $\mathrm{a}$ & \\
\hline
\end{tabular}

$\sqrt{ }$ : present; $\diamond$ : likely present, but noise in spectra masks several peaks

a Possibly present in small amount.

reference sample for comparison. It can be seen that the first order derivative specular distorted carbonyl peak of the oil at $1754 \mathrm{~cm}^{-1}$ corresponds well to the peak found in the sample at $1752 \mathrm{~cm}^{-1}$. Once again, the Kramers-Kronig correction helped in the identification of the oil binder by correcting the main peak at $1730 \mathrm{~cm}^{-1}$ and the peaks around $1161 \mathrm{~cm}^{-1}$ to $1230 \mathrm{~cm}^{-1}$. A reststrahlen band may also be present at the lower limits of the spectrum of point 10; unfortunately, the end of the distortion is below the detection limits of the instrument. Finally, the spectrum of point 2 (Fig. 7), the brown area on the building, clearly shows a specular distorted $\mathrm{C}=\mathrm{O}$ peak at $1752 \mathrm{~cm}^{-1}$ which may be assigned to an oil, as well as, additional peaks around $1465 \mathrm{~cm}^{-1}, 1300 \mathrm{~cm}^{-1}$ and $1052 \mathrm{~cm}^{-1}$, which likely are evidence of a resin, the specific one unknown; however, all these peaks correspond well with the turpentine reference. The carbonyl peak in the resin around $1727 \mathrm{~cm}^{-1}$ is not observed, either because of the first order derivative specular distortion of the carbonyl peak of the oil or because the carbonyl peak of the aged resin has shifted to a higher wave number [8], closer to the carbonyl absorption of the oil. The Kramers-Kronig correction helped reveal a peak at the lower end of the spectrum around $1037 \mathrm{~cm}^{-1}$ which was attributed to the resin. The presence of a resin material corresponds with the literature which states that a varnish layer was often painted over the dried coloured paint layers [4]. The same results of mixed media over the magic lantern plate were observed for the Ponte del Diavolo-Notte. Table 1 shows the binders that have been identified for each point on both glass magic lantern plates. A summary of the main peaks observed in the mid-IR FORS and Kramers-Kronig corrected regions of the mid-IR FORS spectra of points 2, 8 and 10, as well as the reference materials in Table 2; in the case of the reference materials, the absorbance peaks in ATR are also reported for comparison purposes. The assigned peaks do not correspond exactly to each other, because of the noise in the spectra and the smoothing procedure.

These results correspond well with the results from previous FTIR-ATR studies of the binding materials on these painted glass plates [9]. To perform the ATR studies, the plates were gently placed over the ATR window and lightly pressed down to ensure minimal contact. This technique is non-destructive; however, used in this fashion, with such delicate objects, it is invasive to small extent and, above all, if too much pressure is
Table 2

Attenuated total reflectance (ATR), fibre-optic reflectance spectroscopy (FORS) and corrected FORS peak comparison of the three sample points examined in detail and the reference materials.

\begin{tabular}{|c|c|c|c|}
\hline Samples & $\operatorname{ATR}\left(\mathrm{cm}^{-1}\right)$ & FORS $\left(\mathrm{cm}^{-1}\right)$ & $\begin{array}{l}\text { Kramers-Kronig } \\
\left(\mathrm{cm}^{-1}\right)\end{array}$ \\
\hline \multicolumn{4}{|l|}{ References } \\
\hline \multicolumn{4}{|l|}{ Gum arabic } \\
\hline $\mathrm{O}-\mathrm{H}^{\mathrm{a}}$ & 1620 & 1670 & 1602 \\
\hline $\mathrm{C}-\mathrm{H}^{\mathrm{b}}$ & 1360 & 1456 & 1343 \\
\hline $\mathrm{C}-\mathrm{O}^{\mathrm{b}}$ & 1024 & 1170 & 1074 \\
\hline \multicolumn{4}{|c|}{ Rabbit skin glue } \\
\hline $\mathrm{C}=\mathrm{O}^{\mathrm{b}}$ & 1632 & $1704^{\mathrm{c}}$ & 1659 \\
\hline $\mathrm{C}-\mathrm{N}-\mathrm{H}^{\mathrm{a}}$ & 1539 & $1578^{c}$ & 1552 \\
\hline $\mathrm{C}-\mathrm{H}^{\mathrm{a}}$ & 1450 & - & 1454 \\
\hline \multicolumn{4}{|c|}{ Venetian turpentine } \\
\hline $\mathrm{C}=\mathrm{O}^{\mathrm{b}}$ & 1695 & $1735^{\mathrm{c}}$ & 1695 \\
\hline $\mathrm{C}-\mathrm{H}^{\mathrm{a}}$ & 1446 & 1465 & 1439 \\
\hline $\mathrm{C}-\mathrm{O}^{\mathrm{b}}$ & 1038 & $1065^{\mathrm{c}}$ & $1018^{d}$ \\
\hline \multicolumn{4}{|l|}{ Linseed oil } \\
\hline $\mathrm{C}=\mathrm{O}^{\mathrm{b}}$ & 1742 & $1754^{\mathrm{c}}$ & 1735 \\
\hline $\mathrm{C}-\mathrm{H}^{\mathrm{a}}$ & 1459 & 1478 & 1456 \\
\hline $\mathrm{C}-\mathrm{O}^{\mathrm{b}}$ & 1161 & 1187 & 1167 \\
\hline \multicolumn{4}{|l|}{ Sample points } \\
\hline \multicolumn{4}{|c|}{ Point $2-$ oil/resin } \\
\hline $\mathrm{C}=\mathrm{O}^{\mathrm{b}, \mathrm{f}}$ & & $1752^{\mathrm{c}}$ & 1732 \\
\hline $\mathrm{C}-\mathrm{H}^{\mathrm{a}, \mathrm{e}, \mathrm{f}}$ & & 1465 & 1452 \\
\hline $\mathrm{C}-\mathrm{O}^{\mathrm{b}, \mathrm{e}}$ & & 1052 & 1037 \\
\hline \multicolumn{4}{|l|}{ Point 8 - gum } \\
\hline $\mathrm{O}-\mathrm{H}^{\mathrm{a}}$ & & 1652 & 1586 \\
\hline $\mathrm{C}-\mathrm{H}^{\mathrm{b}}$ & & 1456 & 1380 \\
\hline $\mathrm{C}-\mathrm{O}^{\mathrm{b}}$ & & 1143 & 1087 \\
\hline \multicolumn{4}{|l|}{ Point $10-$ oil } \\
\hline $\mathrm{C}=\mathrm{O}^{\mathrm{b}}$ & & $1754^{\mathrm{c}}$ & 1732 \\
\hline $\mathrm{C}-\mathrm{H}^{\mathrm{a}}$ & & 1307 & 1456 \\
\hline $\mathrm{C}-\mathrm{O}^{\mathrm{b}}$ & & 1183 & 1163 \\
\hline
\end{tabular}

a Bending band.

b Stretching band.

c Distorted peak (values of upper cusp).

d Bumpy peak, average value reported.

e Turpentine (evidence of resin).

f Oil (evidence of oil). 
applied or if the plates are not placed correctly, it runs a high risk of being destructive as well.

\section{Conclusions}

Although mid-IR FORS has some limitations, it has been successfully used to non-invasively characterise the binding media used in the creation of painted glass magic lantern plates. Being delicate and fragile artefacts, a non-invasive technique such as mid-IR FORS was ideal for the analysis of the binding materials. In general, reference samples or knowledge of the sample is extremely helpful; thus, four references based on the literature were prepared on glass plates and analysed. The Kramers-Kronig correction was used to help interpret the fingerprint regions of the spectra collected, correcting several peaks, which were distorted because of specular reflection. Oil and watercolour binding materials were identified, as well as a resin material. This suggests that an oil/resin painting medium or an oil medium with a resin varnish layer were used, as well as a gum preparation layer, or painting medium, in the decoration of the glass plates. The presence of all these materials corresponded to document painting methods of glass plates for magic lanterns.

\section{Acknowledgements}

The authors would like to thank Donata Pesenti and Roberta Basano from the Museo Nazionale del Cinema, Torino, Italy, for allowing access to the magic lanterns in their collection. Many thanks also to Pr Tagliaferro and Dr E. Descrovi from the department of Physics at the Politecnico of Torino for helping with the interpretation of the spectral distortions.

\section{References}

[1] R. S. Williams, On-site non-destructive mid-IR spectroscopy of plastics in museum objects using a portable FTIR spectrometer with fiber optic probe, in: P.B. Vandiver, J.R. Druzik, J. F. Merkel, J. Stewart (Eds.), Materials Issues in Art and Archaeology V (vol. 462), Boston, December 3-5, 1996, Materials Research Societry, Warrendale, USA (1997) 25-30.

[2] R. S. Williams. In situ mid-IR spectroscopic analysis of objects at museums using portable IR spectrometers, in: M. Picollo (Ed.), The sixth infrared and Raman users group conference, Florence, March 29-April 1, 2004, Il Prato, Saonara (Padova), Italy (2005) 170-177.

[3] M. Fabbri, M. Picollo, S. Porcinai, M. Bacci, Mid-infrared fibre optics reflectance spectroscopy: a non-invasive technique for remote analysis of painted layers. Part I: Technical setup, Appl. Spec. 55 (2001) 420-427.

[4] T.C. Hepwarth, The Book of the Lantern, Wyman \& Sons, London, 1888.

[5] C. Ricci, C. Miliani, B.G. Brunetti, A. Sgamellotti, Non-invasive identification of surface materials on marble artifacts with fibre-optic mid-FTIR reflectance spectroscopy, Talanta. 69 (2006) 1221-1226.

[6] M. Bacci, R. Bellucci, C. Cucci, C. Frosinini, M. Picollo, S. Porcinai, B. Radicati. Fiber optics reflectance spectroscopy in the entire VIS-IR range: a powerful tool for the non-invasive characterization of paintings, in: P.B. Vandiver, J.L. Mass, A. Murray (Eds.), Materials Issues in Art and Archaeology VII (vol. 852), Boston, November 30-December 3, 2004, Materials Research Society, Warrendale, USA (2005) 297-302.

[7] L. Balcerzak, C. Cucci, M. Picollo, B. Radicati, S. Porcinai, M. Bacci. Noninvasive fiber optic reflectance mid-infrared spectroscopic analysis of white painted layers. in M Picollo (Ed.), The sixth infrared and Raman users group conference, Florence, March 29 - April 1, 2004, Il Prato, Saonara, Italy, 2005, 163-168.

[8] D. Scalarone, M. Lazzari, O. Chiantore, Ageing behaviour and pyrolytic characterisation of diterpenic resins used as art materials: colophony and venice turpentine, J. Anal. Appl. Pyrol. 64 (2002) 345-361.

[9] D. Scalarone, A. Agostino, O. Chiantore, R. Basano. Vetri da proiezione dipinti per lanterne magiche: Analisi non invasive di leganti e pigmenti, in: V. Dell' Aquila (Ed.), Lo stato dell'arte: congresso nazionale IG-IIC, Siena, September 28-30, Italy, (2006) 63-70. 